
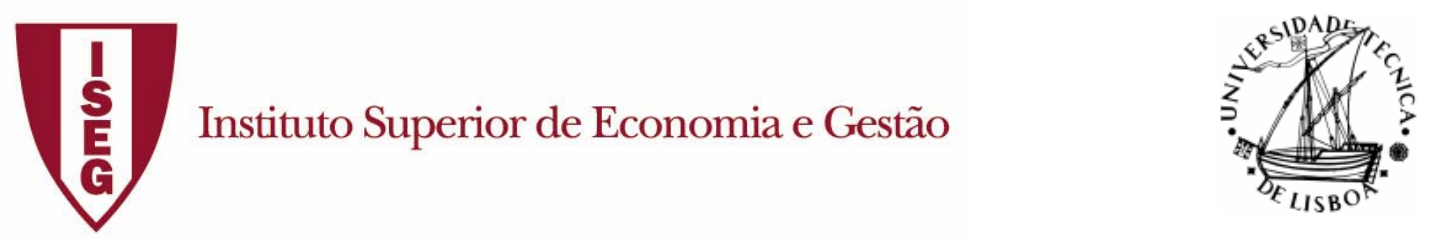

\title{
INFLATION ANNOUNCEMENTS, FEDERAL RESERVE BIAS AND STOCK RETURNS
}

\author{
MIGUEL COELHO ${ }^{\dagger}$ \\ Universidade Técnica de Lisboa \\ Instituto Superior de Economia e Gestão \\ Rua Miguel Lupi, 20, 1249-078 Lisboa, \\ Portugal \\ Tel. +351 213925800 \\ CMVM - Comissão do Mercado de \\ Valores Mobiliários \\ Avenida da Liberdade, 252, 1200 Lisboa, \\ Email: miguelcoelho@cmvm.pt \\ JOÃO DUQUE ${ }^{\dagger+}$ \\ Universidade Técnica de Lisboa \\ Instituto Superior de Economia e Gestão \\ Rua Miguel Lupi, 20, 1249-078 Lisboa, Portugal \\ Tel. +351213925800 \\ Email:jduque@iseg.utl.pt
}

\footnotetext{
${ }^{\dagger}$ The opinions and conclusions do not express in any way the opinions of CMVM, and cannot be used in any circumstances in processes related to CMVM.

†+ Financial support granted by the Fundação para a Ciência e a Tecnologia (FCT) is gratefully acknowledged.
} 



\title{
INFLATION ANNOUNCEMENTS, FEDERAL RESERVE BIAS AND STOCK
}

RETURNS

\begin{abstract}
In this article, we found that the US stock prices react only to the unexpected component of US inflation announcements, with such impact statistically significant only in a situation of economic recession. We also show that the impact of the unexpected component of inflation announcements is also dependent upon the "signals" that the Federal Reserve sends to the market (the known Federal Reserve Bias). In fact, we found a negative correlation between the unexpected component of macroeconomic announcements and stock price returns, this correlation being statistically significant when the Federal Reserve discloses a Neutral Bias.
\end{abstract}

JEL Classification: E44 e G14.

Keywords: Stock Prices; Inflation Announcement; Federal Reserve Bias. 


\section{Introduction}

Some studies support the idea that stock prices react to the unexpected component of several macroeconomics announcements (Feldstein and Summers (1979), Feldstein (1980) and Flannery and Protopapadakis (2002)) and that such impact is not the same across different stages of the business cycle (McQueene and Roley (1993)).

In this study, we tested these two hypotheses using US stock prices and US inflation announcements, and we found that the stock prices react only to the unexpected component of these announcements, with such impact statistically significant only in a situation of economic recession.

Considering that the impact of these inflation announcements may not have the same dimension in all economic activities, we evaluated the impact of announcements for several S\&P500 sector-based indexes and we found that the impact of unexpected component of inflation announcements does not occur in the oil and planes-sector based indexes.

Assuming that the disclosure of information by the Federal Reserve has contributed to a significant improvement in the capacity of the agents to anticipate the future decisions of the FOMC ${ }^{1}$ (Poole and Rasche (2000)), we found that the reaction of stock prices also

\footnotetext{
${ }^{1}$ Federal Open Market Committee.
} 
INFLATION ANNOUNCEMENTS, FEDERAL RESERVE BIAS AND STOCK RETURNS

depends on the signals the Federal Reserve send to the market. In fact, there is a negative correlation between the unexpected component of macroeconomic announcements and stock returns and this correlation is statistically significant in situations where the Federal Reserve discloses a Neutral Bias to the market.

\section{Literature Review}

There is no consensus in the economic literature regarding the relation between macro variables and asset prices. In fact, if Pearce and Roley (1983), Smith and Goodhart (1985), Hardouvelis (1987), Tessaromatis (1990) and Peel, Pope and Paudyal (1990) have shown that asset prices react specifically to monetary information (namely money supply announcements), on the other hand, regarding other macro variables, especially those related with inflation and real business, the conclusions are not that strong. For instance, while Pearce and Roley (1985) have concluded that the stock prices react to monetary information, but do not react to inflation, unemployment and industrial output, Chen, Roll and Ross (1986) have concluded that the rate of growth of industrial output, is a strong candidate as an explanatory factor for stock returns.

Regarding the impact of inflation on stock prices, literature has divided the analysis around two fundamental axes. On one side, there is the identification of the relation between level of inflation and stock returns and, on the other, the evaluation of the impact of news about inflation on stock returns. 
INFLATION ANNOUNCEMENTS, FEDERAL RESERVE BIAS AND STOCK RETURNS

Regarding the first axis, Fama (1981), Geske and Roll (1983) and Kaul (1987) point out the existence of a negative correlation between real stock returns and the level of inflation. According to these authors, the negative correlation between inflation and real stock returns is driven by the negative relation between inflation and future real business, and between this and the expected dividends.

As regards the impact of inflation announcements on stock prices, research has been carried out studying the effects of its expected and unexpected components. The literature demonstrates that, if for the majority of the authors ${ }^{2}$ there is no effect from the expected component of the announcements on stock prices (which support the market efficiency hypothesis), in respect to the unexpected component, the consensus is limited.

In fact, if for Kessel (1956) the increase of the unexpected component has a positive impact on stock prices when the issuer is a net debtor, for Feldstein and Summers (1979), Feldstein (1980) and Flannery and Protopapadakis (2002), the increase of the unexpected component has the opposite effect. On the other hand, the results of Pearce and Roley (1985) and Joyce and Read (1999) ${ }^{3}$ are clearly more ambiguous, since, according to

${ }^{2}$ Please refer to, among others, Day (1984), Pearce and Roley (1985), Danthine and Donaldson (1986), Stulz (1986), Marshal (1992), Mcqueen and Roley (1993) or Joyce and Read (1999).

3 They found that, in the UK market, only Treasury Bonds react significantly to inflation rate announcements (particularly between 1992 and 1997). 
INFLATION ANNOUNCEMENTS, FEDERAL RESERVE BIAS AND STOCK RETURNS

them, there is no evidence that the unexpected component of the announcement has any effect on stock prices. ${ }^{4}$

According to McQueene and Roley (1993) the ambiguity of these findings may result from the fact that the majority of the studies assume that the reaction of investors to announcements is independent of the stage of the business cycle. For these authors, such assumptions can bias the results, since if an announcement is "good" in a specific moment of the business cycle and "bad" in another, the coefficient associated with the unexpected component of the estimated model tends to be zero. ${ }^{5}$

Thus, McQueen and Roley (1993) showed that the impact of the unexpected component of those announcements on stock prices would differ according to the moment of the business cycle at which the announcement is made. Using an econometrical model where global economic conditions were incorporated, defined by the monthly rate of growth of industrial output, it was concluded that the stock price reaction to the surprise announcements of the unexpected component of inflation varies according to the phase of the business cycle, being negative during the medium phase of the business cycle for the CPI (Consumer Price Index) and in the expansion phase for PPI (Producer Price Index).

${ }^{4}$ Lee (1999) considers that the negative correlation between the unexpected component of inflation announcements and ex post real stock returns is induced by the negative correlation between the risk premium and ex post real stock returns.

\footnotetext{
${ }^{5}$ Regarding this subject, see also Boyd et al. (2001). According to these authors, "stock prices rise on bad labour market news during expansions, and fall during contractions”.
} 
However, in our opinion, it is insufficient to consider the business cycle elements when studying the impact of macroeconomic variable announcements on the stock price behavior. First, it is not expected that the reaction of the market to announcements (for example, an inflation rate above expectation) will be the same under high unemployment and, simultaneously, high inflation (stagflation), or under high unemployment and low inflation (recession). On the other hand, the literature that considers the business cycle does not take into consideration the expectation of the agents on the announcement date, regarding the phase of the business cycle, but the ex post perspective of the authors' issue on the date that the studies are prepared.

The economic literature has not given a complete answer to a set of other problems associated with announcements. For example, we did not find in the literature any reference to the relation between macro-economic announcements, stock returns and the signs that the monetary authority sends to the market. That is, in the literature no relevance is given to the signs that the monetary authority sends to the market regarding possible future developments in the stance of the monetary policy, which, in the case of the Federal Reserve, is the so-called Bias of the monetary policy.

\section{Theoretical Framework}

Economic literature presents a set of theories that try to explain the reaction of stock prices to the announcements of inflation. One of the theories justifies the negative correlation between stock price returns and the level of inflation, on the basis of the 
INFLATION ANNOUNCEMENTS, FEDERAL RESERVE BIAS AND STOCK RETURNS

negative correlation between inflation and future output. In accordance with Fame (1981) and Kaul (1987) this can be explained by (i) the positive correlation between inflation level and inflation uncertainty and by (ii) the negative correlation between inflation uncertainty and real economic activity. In fact, an increase in the inflation uncertainty makes the real profits in the future, associated with the investment, more uncertain, reducing current investment and, consequently, the future output (ceteris paribus). According to Lee (1999) “considering that the expected inflation represents the inflation level, it underlies that the expected inflation is the variable that is correlated with future output and, consequently, with the current stock returns”.

On the other hand, according to Pearce and Roley (1985), the previous analysis should not be limited to the expected component of inflation, but also to the unexpected component. Assuming that an inflation announcement above expectation induces the agents to increase the level of expected inflation, then the inflation uncertainty will also be higher and, consequently, this generates a smaller future output with a negative effect on today’s stock prices.

Another hypothesis to explain the impact of inflation announcements on stock price returns, is based on the expectation that the agent has regarding the potential reaction of the monetary policy in reply to this news. According to Joyce (1999), the theories that are based on this relation are the following: the hypothesis of political anticipation (HPA) and the hypothesis of expected inflation (HEI).

According to the HPA, if the current inflation is above (below) the expectations of the market, then the market expects that the monetary authorities restrict (relax) the monetary 
INFLATION ANNOUNCEMENTS, FEDERAL RESERVE BIAS AND STOCK RETURNS

policy (i.e. increase (reduce) the interest rate), with consequent reduction (increase) of the stock price.

On the other hand, and in accordance with the HEI, if the current inflation is above (below) the expected inflation, the market will raise (lower) the future expected inflation, with consequent effect on real interest rates.

As we can see, these two hypotheses are based on the idea that the implementation of the monetary policy has a single objective: price stability. Nevertheless, this is not what happens in reality. In fact, for the Federal Reserve, the decisions of monetary policy have two main objectives: price stability and sustainable economic growth. ${ }^{6}$

Notice that the knowledge of reaction function of the monetary authority by the economic agents is particularly important when we assume rational expectations. In fact, the modelling of the agent's behaviour will inevitably have to incorporate its expectations regarding the implementation of monetary policy. ${ }^{7}$ In this context, it is important to underline the effort made by the Federal Reserve in recent years to improve the transparency of its monetary policy decision process. From among these initiatives we would highlight the following:

a) the announcements of the monetary policy changes, expressed by the changes in the value of the Fed Fund rates;

${ }^{6}$ See Taylor (1993) and Clarida, Galí and Gertler (1997). 
b) the disclosure by FOMC of the evaluation of the risks that the economy has to face $(\text { Bias })^{8}$;

c) the change of the Fed Fund rates between pre-programmed meetings of the FOMC carried out in extraordinary circumstances.

This disclosure of information has contributed, according to Poole and Rasche (2000), to a significant improvement in the capacity of the agents to anticipate the future decisions of the FOMC.

If we associate this increase in transparency with the fact that the economic agents are now revealing greater sensitivity to macroeconomic announcements than to the decisions of monetary policy, we are led to conclude that the previously mentioned elements can influence the reply of the agents to macroeconomic announcements.

In this context, we think that the disclosure of the FOMC opinion regarding the risks that the economy may have to face (Bias) is very important, since we expect that the

${ }^{7}$ For more details see Poole and Rasche (2000).

${ }^{8}$ Tightening Bias when the Fed announces "the risks are weighted mainly toward conditions that may generate heightened inflation pressures in the foreseeable future”; Easing Bias when the Fed announces "the risks are weighted mainly toward conditions that may generate economic weakness in the foreseeable future" and Neutral Bias when the Fed announces, "the risks are balanced with respect to the prospects for both goals (price stability and sustainable economic growth)”. 
INFLATION ANNOUNCEMENTS, FEDERAL RESERVE BIAS AND STOCK RETURNS

monetary policy will react accordingly. Consequently, the decisions of market agents will be influenced, in a whole or in part, by this information.

Therefore, and assuming that the expectation of the agents regarding the evolution of monetary policy depends on the Bias that Federal Reserve discloses to the market, it is expected that the impact of macroeconomic announcements on stock prices also depends on that. This means, for example, that the expectation of agents regarding a climb in Fed Fund rates after the announcement of an unexpected rise in inflation rate in a situation of Easing Bias will not be identical to the one that occurs in a situation of Neutral or Tightening Bias, and consequently, the impact on stock prices of this unexpected rise in inflation rate will not be the same.

\section{Methodology}

In this study we test 4 distinct reactions: i) the stock price reaction to macroeconomic announcements: expected versus unexpected component; ii) the asymmetrical response of stock prices to macroeconomic announcements; iii) the stock price reaction to macroeconomic announcements and business cycle; iv) the stock price response to macroeconomic announcements and the Federal Reserve Bias. 


\section{IV.1. Stock price reaction to macroeconomic announcements: expected versus unexpected component}

To evaluate the stock price reaction to expected and unexpected components of inflation announcements, we will consider the following econometric model.

$$
\Delta P_{t}=\beta_{1}+\beta_{2}\left(\pi_{t}-\pi_{t}^{e}\right)+\beta_{3} \pi_{t}^{e}+\sum_{i=1}^{n}\left(\pi_{t-n}-\pi_{t-n}^{e}\right) \beta_{3+i}+\varepsilon_{t}
$$

In Equation $1 \pi_{t}$ represents the value of the variable announced at moment $\mathrm{t}, \pi_{t}^{e}$ corresponds to the expectation of the market regarding the value of the variable to be announced at time $\mathrm{t}$ and $\Delta P_{t}$ represents the daily instantaneous rate of return at time $\mathrm{t}$. The expectation of the market regarding the value a variable at time $t$ is assumed to be based on all the available information at that time and is formulated by the agents within a time period (with variable size) immediately before that of time $\mathrm{t}$ - within the time interval [t-k; $\mathrm{t}[$.

The instantaneous rate of return is calculated by the logarithmic difference of prices ( $\Delta P_{t}=\ln \left(\frac{P_{t}}{P_{t-1}}\right)$ ) where $P_{t}$ represents the value of the stock index at moment t.

In Equation 1 we have $\sum_{i=1}^{n}\left(\pi_{t-n}-\pi_{t-n}^{e}\right) \beta_{3+i}$ which corresponds to the sum of all unexpected components of previous announcements carried out through time until t-1 (with $\mathrm{n}=$ number of months) and $\varepsilon_{t}$ represents the residuals that are not correlated with the information available during the time period that precedes moment $\mathrm{t}$. 
INFLATION ANNOUNCEMENTS, FEDERAL RESERVE BIAS AND STOCK RETURNS

Knowing that the inflation announcements are at regular monthly intervals and considering that the speed of adjustment of the market to new information takes less than one month ${ }^{9}$, we can assume that the parameters $\beta_{3+i}=0$ (with $\mathrm{i}=1,2 \ldots, \mathrm{n}$ ). Then Equation 1 can be reduced to:

$\Delta P_{t}=\beta_{1}+\beta_{2}\left(\pi_{t}-\pi_{t}^{e}\right)+\beta_{3} \pi_{t}^{e}+\varepsilon_{t}$ (Equation 2)

On the basis of this Equation 2, we test the efficient market hypothesis. If this hypothesis holds, then $\beta_{3}$ parameter should equal zero, meaning that the expected component of inflation was already taken into account in market prices when announcements occurred.

In order to study in-depth the unexpected component when announced, it is also important to evaluate not only the size of the impact but also its proportionality on stock price returns. In order to do so we estimated the model expressed by Equation 3, that does not change the conclusions obtained from Equation 2 and enables us to detect the linearity of the relation under scope.

$$
\Delta P_{t}=\beta_{1}+\beta_{2}\left(\pi_{t}-\pi_{t}^{e}\right)^{3}+\varepsilon_{t}
$$

\section{(Equation 3)}

Assuming that the impact on stock prices of the unexpected inflation announcements (either positive or negative) should have a symmetrical and negative relation (i.e. a positive (negative) unexpected component has a negative (positive) impact in the stock

\footnotetext{
${ }^{9}$ According to Ederington and Lee (1993), “Most of the price adjustment to these information releases (economic information) occurs within one minute of the release and trading profits based on the initial reaction basically disappear within this period”.
} 
prices) and simplifying the notation, considering $\pi_{u}=\left(\pi_{t}-\pi_{t}^{e}\right)$ then this can only happen if :

$$
\frac{\partial \Delta P_{t}}{\partial \pi_{u}}<0
$$

(Equation 4)

But, if both the models of Equation 3 and Equation 4 hold, then

$\frac{\partial^{2} \Delta P_{t}}{\partial \pi_{u}^{2}}>0$ when and only when $\pi_{u}<0$ and,

$\frac{\partial^{2} \Delta P_{t}}{\partial \pi_{u}^{2}}<0$ when and only when $\pi_{u}>0$.

If the second derivative differs from zero we can conclude that stock price return changes (in absolute terms), grow at a rising rate with the change in absolute value with the unexpected inflation component. This means that the relative impact of an announcement on stock prices increases with the size of the unexpected component of the announcement.

\section{IV.2. Asymmetrical response of stock price returns to macroeconomic announcements}

As referred to previously, the majority of studies assumes that stock price reaction to the expected inflation component of macroeconomic announcements is symmetrical. That is, an inflation announcement that ends up above the foreseen one leads to a fall in stock prices, while an announcement below the foreseen one leads to a positive stock price reaction. However, according to Joyce and Read (1999), this symmetry need not 
INFLATION ANNOUNCEMENTS, FEDERAL RESERVE BIAS AND STOCK RETURNS

necessarily occur, even in theoretical terms. To check this hypothesis, we tested the following model where two dummy variables are introduced:

$\Delta P_{t}=\beta_{1}+\beta_{2} D_{1}^{+}\left(\pi_{t}-\pi_{t}^{e}\right)+\beta_{3} D_{2}^{-}\left(\pi_{t}-\pi_{t}^{e}\right)+\varepsilon_{t}$

(Equation 5)

In Equation $5 D_{1}^{+}=1$ if the unexpected component is positive, that is, $\left(\pi-\pi^{e}\right)>0$, and $D_{1}^{+}=0$ otherwise; $D_{2}^{-}=1$ if the unexpected component is negative, that is, $\left(\pi-\pi^{e}\right)<0$, and $D_{1}^{+}=0$ otherwise.

If the response of stock prices to a positive unexpected component has the same magnitude (in absolute term) as the response to a negative unexpected component, then we expect that $\left|\beta_{2}\right|=\left|\beta_{3}\right|$. Similar conclusions can be obtained from Equation 6 and Equation 7 if the effects are treated independently.

$$
\begin{array}{ll}
\Delta P_{t}=\beta_{1}+\beta_{2} D^{-}\left(\pi_{t}-\pi_{t}^{e}\right)+\varepsilon_{t} & \text { (Equation 6) } \\
\Delta P_{t}=\beta_{1}+\beta_{2} D^{+}\left(\pi_{t}-\pi_{t}^{e}\right)+\varepsilon_{t} & \text { (Equation 7) }
\end{array}
$$

However, this has the advantage of treating in-depth, as we did previously with Equation 3 , the non-linear shape of the relation between the unexpected component and stock price returns.

If stock price returns react asymmetrically to macroeconomic announcements, then the derivatives of Equation 8 and Equation 9 will differ. We test the existence of a constant proportionality between the dimension of the surprise component of an announcement and the stock price reaction. For this, we estimate the following models:

$$
\begin{aligned}
& \Delta P_{t}=\beta_{1}+\beta_{2} D^{-}\left(\pi_{t}-\pi_{t}^{e}\right)^{2}+\varepsilon_{t} \\
& \Delta P_{t}=\beta_{1}+\beta_{2} D^{+}\left(\pi_{t}-\pi_{t}^{e}\right)^{2}+\varepsilon_{t}
\end{aligned}
$$

\section{(Equation 9)}


INFLATION ANNOUNCEMENTS, FEDERAL RESERVE BIAS AND STOCK RETURNS

From Equation 8 we conclude that in order to have an increasing impact on stock price at an increasing rate with the rise (in absolute terms) of the unexpected component, then:

$\frac{\partial^{2} \Delta P_{t}}{\partial \pi_{u}^{2}}>0$

But, on the other hand, from Equation 9 we know that in order to have a decreasing impact on stock price at an increasing rate with the rise (in absolute terms) of the unexpected component, then:

$$
\frac{\partial^{2} \Delta P_{t}}{\partial \pi_{u}^{2}}<0
$$

\section{IV.3. Stock price response to macroeconomic announcements and business cycle}

In line with previous studies, namely McQueen and Roley (1993), we tested the hypothesis that the response of the stock prices to inflation announcements is conditional upon the business cycle phase. For this, we estimated the following model:

$$
\Delta P_{t}=\beta_{1}+\beta_{2} D_{E X P}\left(\pi_{t}-\pi_{t}^{e}\right)+\beta_{3} D_{A B R}\left(\pi_{t}-\pi_{t}^{e}\right)+\varepsilon_{t} \quad \text { (Equation 10) }
$$

where $D_{E X P}=1$ if we face an economic expansion and $D_{E X P}=0$ otherwise; $D_{A B R}=1$ if we face an economic recession and $D_{A B R}=0$ otherwise.

If the response of stock prices to the unexpected component of macroeconomic announcements under economic expansion equals the corresponding reaction under an economic recession, we should expect that $\beta_{2}=\beta_{3}$ in Equation 10 . 


\section{IV.4. Stock price response to macroeconomic announcements and Federal Reserve Bias}

Considering that the market is efficient (the stock prices only react to the unexpected component of the announcements) it is important to check the possibility that the reaction is also dependent on Federal Reserve Bias. For such, we assume that the economic agents have a behavior that depends not only on the announcement, but also on the context. In this case the context will correspond to the signals that the Federal Reserve send to the market in the last meeting of FOMC before the announcement. These "signals" (i.e. Bias) may assume 3 different forms: Easing, Neutral and Tightening. To test this hypothesis we estimated the following model:

$$
\Delta P_{t}=\beta_{1}+\beta_{2} D_{1}\left(\pi_{t}-\pi_{t}^{e}\right)+\beta_{3} D_{2}\left(\pi_{t}-\pi_{t}^{e}\right)+\beta_{4} D_{3}\left(\pi_{t}-\pi_{t}^{e}\right)+\varepsilon_{t} \quad \text { (Equation 11) }
$$

Where $D_{1}=1$ if the Federal Reserve Bias (announced just before the macroeconomic announcement) is Easing and $D_{1}=0$ otherwise; $D_{2}=1$ if the Federal Reserve Bias (announced just before the macroeconomic announcement) is Neutral and $D_{2}=0$ otherwise; $D_{3}=1$ if the Federal Reserve Bias (announced just before the macroeconomic announcement) is Tightening and $D_{3}=0$ otherwise.

\section{Data}

As representatives of market stock prices we used daily returns of Nasdaq Index, S\&P

Index and several sector indexes, namely: S\&Paero, S\&Pauto, S\&Pbank, S\&Pcmwh, 
INFLATION ANNOUNCEMENTS, FEDERAL RESERVE BIAS AND STOCK RETURNS

S\&Poilp, S\&Pphar (planes; cars; banks; data processing hardware; oil companies; and drugs, respectively).

As a proxy for inflation expected figures we used a database compiled by Bloomberg (market consensus). It was included in our analysis, 72 observations from November 1996 to November 2002, regarding the market consensus of two macroeconomics variables: CPI, CPI Core.

In order to study the business cycle, and from a methodological point of view, we presumed that the investors assume two possible economic situations: expansion and recession. The expansion (recession) of economic activity corresponds to the months in which the consumer confidence indicator had a rise $(\text { fall })^{10}$. The results obtained are expressed in Figure I and Figure II.

The data regarding the Federal Reserve Bias were compiled from its official site and cover the time period from November 1996 to October 2002. The Bias prominent for each announcement day corresponds to the Bias disclosed by the FOMC meeting previous to the date of disclosure of the macroeconomic indicator - Figure III.

\footnotetext{
${ }^{10}$ Notice that Consumption represents more than $60 \%$ of the US GDP.
} 


\section{Empirical Results}

\section{VI.1. Stock price reaction to inflation announcements: surprise component versus non- surprise}

As observed in previous studies, the results obtained with the estimation of the Equation 2 are according to the support of the efficient market hypothesis for the US stock market. In fact, we did not identify any statistically significant impact of expected component of macroeconomic announcements on stock price returns (all $\beta_{3}$ parameters are statistically insignificant) - Table 1.

Regarding the unexpected component of the announcements, the results aim for the hypothesis of existence of an inverse relation between that component and stock returns observed on the day of the announcements - Table 1. For example, by each 0,1 b.p. of unexpected inflation (using the CPI as an inflation indicator), the return on S\&P500 index on the announcement day will be approximately of -0,47 b.p..

These results seem to confirm the following theoretical hypotheses:

a) the announcement of an inflation above (below) the expectations prompts the agents to increase (diminish) their level of expected inflation, with a consequent increase (reduction) of inflation uncertainty, smaller (bigger) real business activity in the future and, consequently, a decrease (increase) in today's stock prices (ceteris paribus); 
INFLATION ANNOUNCEMENTS, FEDERAL RESERVE BIAS AND STOCK RETURNS

b) the announcement of an inflation above (below) expectations changes the expectations of the agents regarding the behavior of the monetary authority, through the adoption of more (less) restrictive monetary policies, increasing (reducing) the rate of interest, with consequent reduction (increase) of stock prices (ceteris paribus).

Nevertheless, the negative relation between those factors and stock returns cannot be confirmed for all S\&P500 sector-based indexes. Indeed, the Oil and Aeronautic indexes show no statistically significant relation.

On the other hand, we did not find evidence to support the hypothesis that there is a nonlinear relation between inflation announcements and stock returns - Table 2. Indeed, only for the S\&P500, S\&Pauto and S\&Pbank indexes (using the CPI announcements as proxy for inflation announcements) and for the S\&Pbank and S\&Pcmhw (using the CPI Core announcements as the proxy for inflation announcements), we found the parameter $\beta_{2}$ (Equation 3) negative and statistically significant. For these indexes, constant increases in size (in absolute terms) of the unexpected component it provokes increases with growing size (in absolute terms) on the stock indexes returns. From an algebraic point of view we observed that:

$\frac{\partial^{2} \Delta P_{t}}{\partial \pi_{u}^{2}}>0$ when $\pi_{u}<0$ and $\frac{\partial^{2} \Delta P_{t}}{\partial \pi_{u}^{2}}<0$ when $\pi_{u}>0$. 


\section{VI.2. Asymmetric response of stock prices to macroeconomic announcements}

The results obtained from the estimation of Equation 5 support the idea that the response of stock prices to inflation announcements is asymmetrical - Table 3. In fact, for the S\&P500 index, the Nasdaq index and for some of the sector indexes, the reaction to inflation announcements above expectations is negative and statistically significant, but it is not statistically significant from zero in any case when inflation announcements fall below expectations.

This hypothesis is confirmed when we evaluate the probability of the coefficient associated with the positive surprise component of announcement to be equal (in absolute value) to the coefficient associated with the negative surprise component of announcement - Table 4. Identical results are obtained with the estimation of Equation 6 and Equation 7 - Table 5 and Table 6.

In face of this, and taking into account the results obtained with the estimation of Equation 3, we tested whether this asymmetrical reaction is responsible for not having confirmed a nonlinear relation between the size of the unexpected inflation component and stock returns.

In order to do so, we estimated Equation 8 and the results seem to confirm the hypothesis of the absence of a nonlinear relation between stock returns and size of the unexpected inflation component of the announcements, when the unexpected component is negative Table 7. In fact, only the S\&Pphar index (for CPI announcements) and the S\&Pcmhw 
INFLATION ANNOUNCEMENTS, FEDERAL RESERVE BIAS AND STOCK RETURNS

index (for CPI Core announcements) present a positive and statistically significant parameter, which means that the returns of these indexes grow at increasing rates with the changes (in absolute terms) on the unexpected inflation component of the announcement, that is:

$\frac{\partial^{2} \Delta P_{t}}{\partial \pi_{u}^{2}}>0$ with $\pi_{u}=\left(\pi_{t}-\pi_{t}^{e}\right)<0$

However, for CPI announcements with a positive unexpected inflation component, it is observed (using Equation 9) that 5 out of 8 indexes (4 out of 8 for the CPI Core announcements) lead to negative and statistically significant $\beta_{2}$ parameter - Table 8 .. This supports the hypothesis that stock price returns decrease at an increasing rate with changes in the unexpected component of the announcement, that is:

$\frac{\partial^{2} \Delta P_{t}}{\partial \pi_{u}^{2}}<0$ with $\pi_{u}=\left(\pi_{t}-\pi_{t}^{e}\right)>0$

\section{VI.3. Stock price response to macroeconomics announcements and business cycle}

As in McQueen and Roley (1993), the results of adjusting data to Equation 10 allow us to conclude that the response of stock prices to macroeconomic announcements depends on the business cycle. In fact, if choosing the University of Michigan Confidence Index as a proxy for the business cycle, we conclude that the impact of the unexpected inflation component on stock price returns is negative and statistically significant in 6 of 8 S\&P500 sector-based indexes when the economy is in a recession. On the contrary, when the economy is in expansion, the corresponding impact is no longer negative in terms of statistical significance (in only one case, the S\&P500 sector-based index, is the result 
INFLATION ANNOUNCEMENTS, FEDERAL RESERVE BIAS AND STOCK RETURNS

statistically significant) - see Table 9 and Table 10. We found weaker but not dramatically different results when we used as a proxy of business cycle the Conference Board Confidence Index - see Table 11 and Table 12.

\section{VI.4. Stock price response to macroeconomic announcements and Federal Reserve Bias}

The results seem to confirm the hypothesis that the stock price response to macroeconomic announcements depends on issued "signals” by Federal Reserve. Indeed, according to the results obtained from the estimation of parameters for Equation 11, the negative and statistically significant relation between the surprise component of the CPI announcements and stock index returns was only observed when the Federal Reserve issued a Neutral Bias - Table 13. This result seems to be consistent with the hypothesis that the uncertainty about the future development of the monetary policy under Neutral Bias is higher than on other occasions, the unexpected inflation component of the announcement being understood by agents as a leading indicator for future changes in the monetary policy.

In another way, when the Federal Reserve announces an Easing Bias (Tightening), the expectations of the agents are strongly biased towards a reduction (increase) of the Fed Fund rates. This means that the announcement of a positive (negative) unexpected inflation component only strengthens this high probability of an increase (decrease) of the Fed Fund rates. On the contrary, when the Bias is Neutral agents expect that the Fed 
INFLATION ANNOUNCEMENTS, FEDERAL RESERVE BIAS AND STOCK RETURNS

will not change the monetary policy, and the announcement of a positive (negative) unexpected inflation component can be understood by agents as a sign that the monetary policy will be modified, becoming more restrictive (expansive). This means that the announcements of inflation under such circumstances have greater significance for agents.

\section{Conclusion}

The relation between macroeconomic announcements and stock prices has been analyzed in the economic literature of the last decades. These studies have shown that the reaction of the stock prices to these announcements depends on the type of financial asset and macroeconomic variable. On the other hand, some authors consider that the signal and dimension of this relation are conditional on the business cycle.

The purpose of this study was to identify, the impact that US inflation announcements (using CPI and CPI Core) have on US stock indexes.

We conclude that stock prices tend to react only to the unexpected component of inflation announcements. This tends to be especially true when this component is positive (asymmetric reaction). We also found that this reaction is not homogeneous among different sectors under scope. Our study also show that the previous conclusion is also dependent on the business cycle. 
INFLATION ANNOUNCEMENTS, FEDERAL RESERVE BIAS AND STOCK RETURNS

Finally, we found that the reaction of the stock prices also depends on the "signals" (Bias) that the Federal Reserve sends to the market after the meetings of the FOMC. However, this is only true if CPI announcements occur under Neutral Bias “signals”. 


\section{References}

Boyd J., Jagannathan R. and Hu J., 2001, The Stock Market's Reaction to Unemployment News: Why Bad News is Usually Good for Stocks, NBER Working Paper, n. 8092.

Chen, Nai-Fu, Richard R. Roll, and Stephen A. Ross, 1986, "Economic Forces and the Stock Market”, Journal of Business, 59, Vol. III, 383-404.

Clarida, R, Galí, J. and Gertler, M., 1997, Monetary Policy Rules in Practice: Some International Evidence, CEPR Discussion Paper, n. 1750.

Danthine, J. , Donaldson, J., 1986, Inflation and Asset Prices in an Exchange Economy, Econometrica, 54, 585-606.

Day, T., 1984, Real Stock Returns and Inflation, Journal of Finance, 2, Vol. XXXIX, 493-502 .

Ederington, L. and Lee, J., 1993, How Market Process Information: News Releases and Volatility, The Journal of Finance, 4, Vol. XLVII, 1161-91.

Fama, E. F., 1981, Stock Returns, Real Activity, Inflation, and Money, American Economic Review, 71, 545-65.

Feldstein, M. and Summers, L., 1979, Inflation and the Taxation of Capital Gains in the Corporate Sector, National Tax Journal, 32, 445-70.

Feldstein, M., 1980, Inflation and Stock Market, American Economic Review, 70, 839-47.

Flannery, M. and Protopapadakis, A., 2002, Macroeconomics Factors do Influence Aggregate Stock Returns, Review of Financial Studies, 15, 751-82

Geske, R. and Roll, R., 1983, The Fiscal and Monetary Linkage Between Stock Returns and Inflation, Journal of Finance, 38, 1-33. 
INFLATION ANNOUNCEMENTS, FEDERAL RESERVE BIAS AND STOCK RETURNS

Hardouvelis, G., 1987, Macroeconomic Information and Stock Prices, Journal of Economics and Business, 39, 253-57.

Joyce, M. and Read, V., 1999, Asset Prices Reactions to RPI Announcements, Working Paper, Bank of England, 94.

Kaul, G., 1987, Stock Returns and Inflation: the Role of the Monetary Sector, Journal of Financial Economics, 18, 128-41.

Kesel, R., 1956, Inflation Caused Wealth Redistribution: A Test of an Hypothesis, American Financial Review, 46, 128-41.

Lee, K., 1999, Unexpected Inflation, Inflation Uncertainty, and Stock Returns, Applied Financial Economics, 9, 315-28.

Marshal, D., 1992, Inflation and Asset Returns in Monetary Economy, Journal of Finance, 47, 1315-42.

McQueen, G. and Roley, V., 1993, Stock Prices, News, and Business Conditions, Review of Financial Studies, 6, 683-707.

Pearce, D. and Roley, V., 1983, The Reaction of Stock Prices to Unanticipated Changes in Money: A Note, Journal of Finance, 38, 1323-33.

Pearce, D. and Roley, V., 1985, Stock Prices and Economic News, Journal of Business, 58, 49-67.

Peel, Pope and Paudical, 1990, The Policy Antecipation Hypothesis and The Expected Inflation Hypothesis - Some New Evidence Using Index Linked Bonds”, Economics Letters, 34, 121-25.

Poole, W. and Rasche, R., 2000, Perfecting the Market's Knowledge of Monetary Policy, Working Paper, Federal Reserve of St. Louis, n. 2000-010A. 
INFLATION ANNOUNCEMENTS, FEDERAL RESERVE BIAS AND STOCK RETURNS

Taylor, J., 1993, Discretion versus Policy Rules in Practice, Carnegie-Rochester Conference on Public Policy, 39.

Smith, R. and Goodhart, C., 1985, The Relationship Between Exchange Rate Movements and Monetary Surprises: Results for the United Kingdom and The United States Compared and Contrasted, The Manchester School, 53, 2-22.

Stulz, R., 1986, Asset Pricing and Expected Inflation, Journal of Finance, 41, 209-23.

Tessaromatis, 1990, Money supply announcements and real interest rates: Evidence from the U.K. index-linked bond market, Journal of Banking \& Finance, Vol. XIV. 


\section{Tables and Figures}

Figure I - University of Michigan Confidence Index and Private Consumption in the US

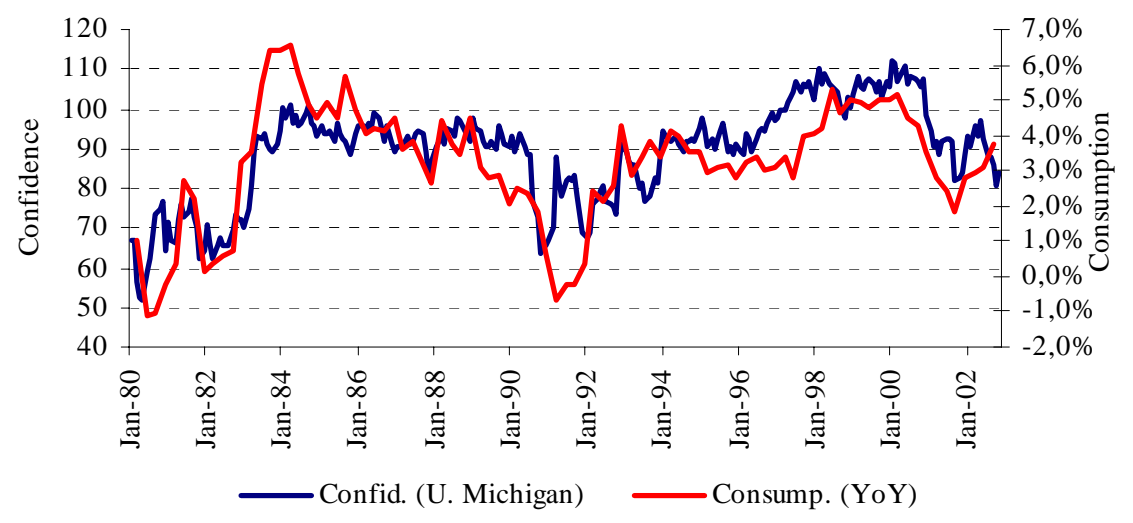

Figure II - Conference Board Confidence Index and Private Consumption in the US

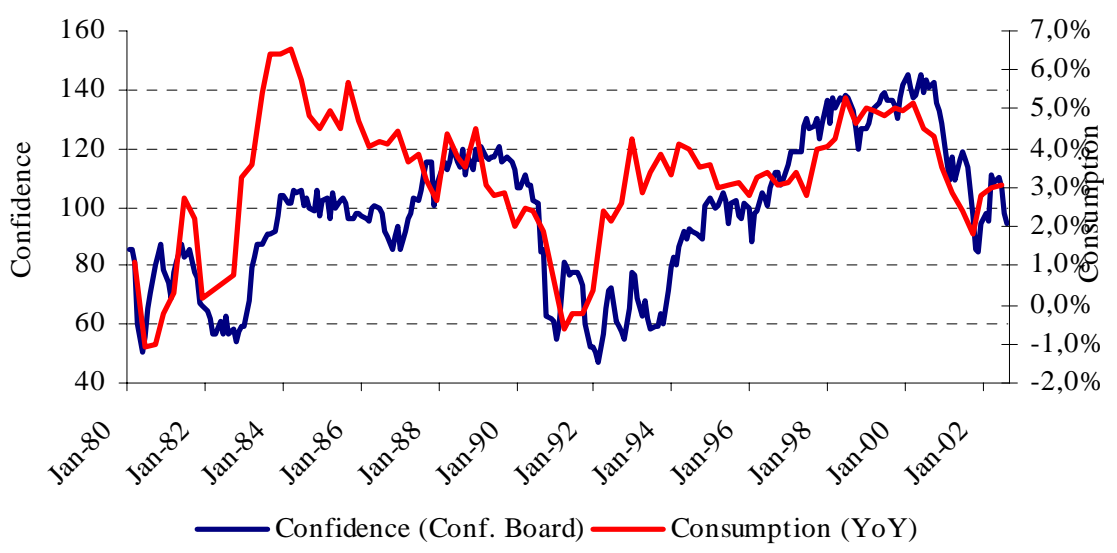




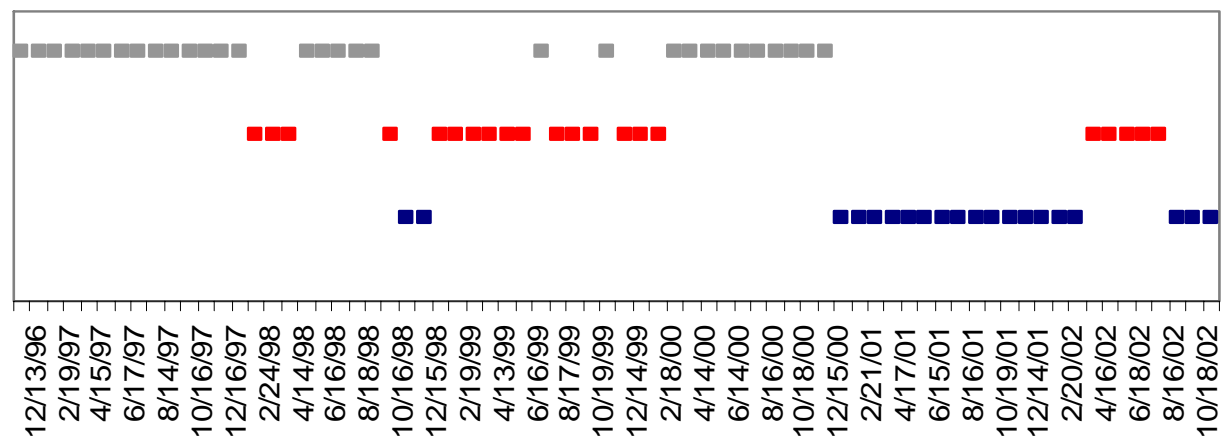

- Easening Neutral $\square$ Tightening

Table 1 - Expected versus Unexpected Component of inflation announcements and stock indexes

\begin{tabular}{lcccccccc}
\hline \multicolumn{7}{c}{ (Equation $\left.2 \Delta P_{t}=\beta_{1}+\beta_{2}\left(\pi_{t}-\pi_{t}^{e}\right)+\beta_{3} \pi_{t}^{e}+\varepsilon_{t}\right)$} \\
\hline & $B_{1}$ & $B_{2}$ & $B_{3}$ & $R^{2}$ & $B_{1}$ & $B_{2}$ & $B_{3}$ & $R^{2}$ \\
\hline S\&P500 & $-0,001$ & $-4,73^{*}$ & $-0,23$ & 0,128 & 0,003 & $-6,77^{*}$ & $-2,07$ & 0,135 \\
S\&Paero & 0,001 & $-2,79$ & $-1,20$ & 0,061 & 0,005 & $-3,39$ & $-3,21$ & 0,036 \\
S\&Pauto & 0,001 & $-7,22^{*}$ & $-1,16$ & 0,162 & 0,003 & $-6,92^{*}$ & $-2,16$ & 0,071 \\
S\&Pbank & $-0,003$ & $-5,97^{*}$ & 0,52 & 0,115 & 0,004 & $-9,07^{*}$ & $-2,49$ & $0,143^{* *}$ \\
S\&Pcmhw & $-0,003$ & $-8,22^{*}$ & 0,04 & 0,133 & 0,010 & $-12,73^{*}$ & $-6,11$ & 0,167 \\
S\&Poilp & 0,004 & $-0,99$ & $-2,82$ & 0,044 & 0,012 & $-0,59$ & $-7,01$ & 0,033 \\
S\&Pphar & $-0,003$ & $-5,73^{*}$ & $-0,50$ & 0,087 & 0,003 & $-6,17$ & $-2,95$ & 0,051 \\
Nasdaq & 0,000 & $-5,69^{*}$ & $-0,92$ & $0,092^{* * *}$ & 0,009 & $-10,37^{*}$ & $-5,20$ & $0,146^{* *}$ \\
\hline
\end{tabular}

* Parameters statistically significant at a 5\% confidence level.

** Heteroskedasticity found and corrected using the White method.

*** Autocorrelation and Heteroskedasticity were found and corrected by using the Newey-West method.

Table 2 - Announcements and linear reaction versus non-linear reaction of stock prices

\begin{tabular}{|c|c|c|c|c|c|c|}
\hline & \multicolumn{6}{|c|}{ (Equation $\left.3 \Delta P_{t}=\beta_{1}+\beta_{2}\left(\pi_{t}-\pi_{t}^{e}\right)^{3}+\varepsilon_{t}\right)$} \\
\hline & \multicolumn{3}{|c|}{ CPI } & \multicolumn{3}{|c|}{ CPI Core } \\
\hline & $B_{1}$ & $B_{2}$ & $R^{2}$ & $B_{1}$ & $B_{2}$ & $R^{2}$ \\
\hline S\&P500 & $-0,001$ & $-664023,9^{*}$ & 0,075 & $-0,001$ & $-2777912,0$ & $0,139^{* * *}$ \\
\hline S\&Paero & $-0,001$ & $-321366,6$ & 0,017 & $-0,001$ & $-1090839,0$ & 0,021 \\
\hline S\&Pauto & $-0,001$ & $-979629,1^{*}$ & 0,082 & 0,000 & $-2942152,0$ & $0,078^{* *}$ \\
\hline S\&Pbank & $-0,001$ & $-745398,3^{*}$ & 0,055 & 0,001 & $-3910434,0^{*}$ & $0,162^{* * *}$ \\
\hline S\&Pcmhw & $-0,002$ & $-1092011,0$ & 0,071 & $-0,001$ & $-3969539,0^{*}$ & 0,100 \\
\hline S\&Poilp & $-0,002$ & $-697962,5$ & 0,044 & $-0,002$ & 266627,0 & 0,001 \\
\hline S\&Pphar & $-0,003$ & $-656436,9$ & 0,124 & $-0,002$ & $-2838235,0$ & 0,066 \\
\hline Nasdaq & $-0,001$ & $-740984,5$ & 0,043 & 0,001 & $-4162064,0$ & $0,145^{* *}$ \\
\hline
\end{tabular}

* Parameters statistically significant at a 5\% confidence level.

** Heteroskedasticity found and corrected using the White method.

*** Autocorrelation and Heteroskedasticity were found and corrected by using the Newey-West method.

Table 3 - Announcements and asymmetrical reaction of stock prices 


\begin{tabular}{|c|c|c|c|c|c|c|c|c|}
\hline & \multicolumn{8}{|c|}{ (Equation $\left.5 \Delta P_{t}=\beta_{1}+\beta_{2} D_{1}^{+}\left(\pi_{t}-\pi_{t}^{e}\right)+\beta_{3} D_{2}^{-}\left(\pi_{t}-\pi_{t}^{e}\right)+\varepsilon_{t}\right)$} \\
\hline & \multicolumn{4}{|c|}{ CPI } & \multicolumn{4}{|c|}{ CPI Core } \\
\hline & $B_{1}$ & $B_{2}$ & $B_{3}$ & $R^{2}$ & $B_{1}$ & $B_{2}$ & $B_{3}$ & $R^{2}$ \\
\hline S\&P500 & 0,002 & $-9,31^{*}$ & $-0,84$ & 0,2472 & 0,001 & $-9,01^{*}$ & $-2,92$ & $0,145^{* *}$ \\
\hline S\&Paero & $-0,001$ & $-7,01$ & 1,26 & 0,058 & 0,001 & $-5,52$ & 0,79 & 0,039 \\
\hline S\&Pauto & 0,001 & $-10,97^{*}$ & $-4,34$ & 0,170 & 0,001 & $-9,64$ & $-2,36$ & $0,078^{* *}$ \\
\hline S\&Pbank & 0,004 & $-13,99^{*}$ & 1,15 & 0,205 & 0,001 & $-11,25^{*}$ & $-5,10$ & 0,147 \\
\hline S\&Pcmhw & 0,000 & $-12,86^{*}$ & $-4,20$ & 0,151 & $-0,001$ & $-13,03^{*}$ & $-9,75$ & 0,153 \\
\hline S\&Poilp & $-0,001$ & $-2,46$ & $-0,61$ & 0,007 & 0,001 & $-2,87$ & 5,44 & 0,015 \\
\hline S\&Pphar & 0,003 & $-6,92$ & $-4,87$ & 0,088 & $-0,002$ & $-7,71$ & $-2,87$ & 0,050 \\
\hline Nasdaq & 0,004 & $-12,98^{*}$ & 0,33 & 0,144 & 0,001 & $-11,72$ & $-6,36$ & $0,136^{* * *}$ \\
\hline
\end{tabular}

* Parameters statistically significant at a 5\% confidence level.

** Heteroskedasticity found and corrected using the White method.

*** Autocorrelation and Heteroskedasticity were found and corrected by using the Newey-West method.

Table 4 - Hypothesis Test: Announcements and asymmetrical reaction of stock prices derived from Equation 4

\begin{tabular}{|c|c|c|c|c|}
\hline & \multicolumn{2}{|c|}{ CPI } & \multicolumn{2}{|c|}{ CPI Core } \\
\hline & $\left|\beta_{2}\right|=\left|B_{3}\right|$ & $\beta_{2}=\beta_{3}=0$ & $\left|\beta_{2}\right|=\left|B_{3}\right|$ & $\beta_{2}=\beta_{3}=0$ \\
\hline S\&P500 & 0,046 & 0,001 & 0,367 & 0,049 \\
\hline S\&Paero & 0,411 & 0,126 & 0,280 & 0,250 \\
\hline S\&Pauto & 0,267 & 0,001 & 0,443 & 0,150 \\
\hline S\&Pbank & 0,001 & 0,000 & 0,405 & 0,004 \\
\hline S\&Pcmhw & 0,230 & 0,003 & 0,730 & 0,003 \\
\hline S\&Poilp & 0,771 & 0,765 & 0,661 & 0,589 \\
\hline S\&Pphar & 0,751 & 0,041 & 0,583 & 0,168 \\
\hline Nasdaq & 0,005 & 0,004 & 0,611 & 0,045 \\
\hline
\end{tabular}

* Parameters statistically significant at a 5\% confidence level.

** Heteroskedasticity found and corrected using the White method.

*** Autocorrelation and Heteroskedasticity were found and corrected by using the Newey-West method.

Table 5 - Announcements and asymmetrical reaction of stock prices - Negative Surprise

\begin{tabular}{|c|c|c|c|c|c|c|}
\hline \multicolumn{7}{|c|}{$\left(\right.$ Equation $\left.6 \Delta P_{t}=\beta_{1}+\beta_{2} D^{-}\left(\pi_{t}-\pi_{t}^{e}\right)+\varepsilon_{t}\right)$} \\
\hline & \multicolumn{3}{|c|}{ CPI } & \multicolumn{3}{|c|}{ CPI Core } \\
\hline & $B_{1}$ & $B_{2}$ & $R^{2}$ & $B_{1}$ & $B_{2}$ & $R^{2}$ \\
\hline S\&P500 & $-0,003$ & $-3,73$ & 0,032 & $-0,003$ & $-6,52$ & 0,041 \\
\hline S\&Paero & $-0,003$ & $-2,81$ & 0,017 & $-0,002$ & $-1,41$ & 0,002 \\
\hline S\&Pauto & $-0,004$ & $-7,75^{*}$ & 0,069 & $-0,003$ & $-6,22$ & 0,018 \\
\hline S\&Pbank & $-0,002$ & $-3,20$ & 0,014 & $-0,004$ & $-9,60$ & 0,053 \\
\hline S\&Pcmhw & $-0,001$ & $-8,20^{*}$ & 0,054 & $-0,006$ & $-14,96^{*}$ & 0,077 \\
\hline S\&Poilp & $-0,003$ & $-1,38$ & 0,002 & $-0,001$ & 4,29 & 0,009 \\
\hline S\&Pphar & $-0,006$ & $-7,02^{*}$ & $0,051^{* *}$ & $-0,005$ & $-5,95$ & 0,016 \\
\hline Nasdaq & $-0,002$ & $-3,69$ & 0,015 & $-0,004$ & $-11,05^{*}$ & 0,055 \\
\hline
\end{tabular}

* Parameters statistically significant at a 5\% confidence level.

** Heteroskedasticity found and corrected using the White method.

*** Autocorrelation and Heteroskedasticity were found and corrected by using the Newey-West method.

Table 6- Announcements and asymmetrical reaction of stock prices - Positive Surprise 


\begin{tabular}{|c|c|c|c|c|c|c|}
\hline & \multicolumn{6}{|c|}{ (Equation $\left.7 \Delta P_{t}=\beta_{1}+\beta_{2} D^{+}\left(\pi_{t}-\pi_{t}^{e}\right)+\varepsilon_{t}\right)$} \\
\hline & \multicolumn{3}{|c|}{ CPI } & \multicolumn{3}{|c|}{ CPI Core } \\
\hline & $B_{1}$ & $B_{2}$ & $R^{2}$ & $B_{1}$ & $B_{2}$ & $R^{2}$ \\
\hline S\&P500 & 0,002 & $-9,63^{*}$ & 0,175 & 0,002 & $-9,80^{*}$ & $0,137^{* *}$ \\
\hline S\&Paero & 0,001 & $-5,49^{*}$ & 0,055 & 0,000 & $-5,30$ & 0,038 \\
\hline S\&Pauto & 0,003 & $-12,61^{*}$ & 0,151 & 0,002 & $-10,29$ & $0,076^{* * *}$ \\
\hline S\&Pbank & 0,004 & $-13,56^{*}$ & 0,204 & 0,003 & $-12,64^{*}$ & $0,134^{* *}$ \\
\hline S\&Pcmhw & 0,003 & $-14,44^{*}$ & 0,138 & 0,002 & $-15,68^{*}$ & 0,124 \\
\hline S\&Poilp & $-0,001$ & $-2,69$ & 0,007 & $-0,002$ & $-1,38$ & 0,001 \\
\hline S\&Pphar & $-0,001$ & $-8,76$ & $0,066^{* *}$ & $-0,001$ & $-8,49$ & 0,047 \\
\hline Nasdaq & 0,003 & $-12,85$ & 0,145 & 0,003 & $-13,46$ & $0,120^{* *}$ \\
\hline
\end{tabular}

* Parameters statistically significant at a 5\% confidence level.

** Heteroskedasticity found and corrected using the White method.

*** Autocorrelation and Heteroskedasticity were found and corrected by using the Newey-West method.

Table 7 - Announcements and linear reaction versus non-linear reaction of stock prices - Negative Surprise

\begin{tabular}{|c|c|c|c|c|c|c|}
\hline & \multicolumn{6}{|c|}{ (Equation $\left.8 \Delta P_{t}=\beta_{1}+\beta_{2} D^{-}\left(\pi_{t}-\pi_{t}^{e}\right)^{2}+\varepsilon_{t}\right)$} \\
\hline & \multicolumn{3}{|c|}{ CPI } & \multicolumn{3}{|c|}{ CPI Core } \\
\hline & $B_{1}$ & $B_{2}$ & $R^{2}$ & $B_{1}$ & $B_{2}$ & $R^{2}$ \\
\hline S\&P500 & $-0,002$ & 1110,6 & 0,012 & $-0,003$ & 6521,1 & 0,041 \\
\hline S\&Paero & $-0,002$ & 616,5 & 0,003 & $-0,002$ & 1414,4 & 0,002 \\
\hline S\&Pauto & $-0,003$ & 2606,6 & 0,034 & $-0,003$ & 6219,7 & 0,018 \\
\hline S\&Pbank & $-0,001$ & 732,9 & 0,003 & $-0,004$ & 9603,6 & 0,052 \\
\hline S\&Pcmhw & $-0,004$ & 2400,6 & 0,020 & $-0,006$ & $14959,4^{*}$ & 0,076 \\
\hline S\&Poilp & $-0,003$ & 1748,2 & 0,016 & $-0,001$ & $-4292,6$ & 0,009 \\
\hline S\&Pphar & $-0,005$ & $2498,7^{*}$ & $0,028^{* *}$ & $-0,005$ & 5956,6 & 0,015 \\
\hline Nasdaq & $-0,002$ & 793,7 & 0,003 & $-0,002$ & 4453,3 & 0,025 \\
\hline
\end{tabular}

* Parameters statistically significant at a 5\% confidence level.

** Heteroskedasticity found and corrected using the White method.

*** Autocorrelation and Heteroskedasticity were found and corrected by using the Newey-West method.

Table 8 - Announcements and linear reaction versus non-linear reaction of stock prices - Positive Surprise

\begin{tabular}{|c|c|c|c|c|c|c|}
\hline & \multicolumn{6}{|c|}{ (Equation $9 \Delta P_{t}=\beta_{1}+\beta_{2} D^{+}\left(\pi_{t}-\pi_{t}^{e}\right)^{2}+\varepsilon_{t}$ ) } \\
\hline & \multicolumn{3}{|c|}{ CPI } & \multicolumn{3}{|c|}{ CPI Core } \\
\hline & $B_{1}$ & $B_{2}$ & $R^{2}$ & $B_{1}$ & $B_{2}$ & $R^{2}$ \\
\hline S\&P500 & 0,001 & $-3653,5^{*}$ & 0,148 & 0,001 & $-5772,5^{*}$ & $0,138^{* *}$ \\
\hline S\&Paero & $-0,000$ & $-2044,3$ & 0,044 & $-0,001$ & $-2689,3$ & 0,029 \\
\hline S\&Pauto & 0,001 & $-4680,8^{*}$ & 0,122 & 0,001 & $-6145,1$ & 0,078 \\
\hline S\&Pbank & 0,002 & $-4771,3^{*}$ & $0,148^{* *}$ & 0,002 & $-7825,3^{*}$ & $0,149^{* *}$ \\
\hline S\&Pcmhw & 0,001 & $-5610,9^{*}$ & 0,122 & 0,001 & $-8190,2^{*}$ & 0,098 \\
\hline S\&Poilp & $-0,001$ & $-1718,6$ & 0,017 & $-0,002$ & $-268,2$ & 0,002 \\
\hline S\&Pphar & $-0,002$ & $-2773,5$ & $0,038^{* *}$ & $-0,001$ & $-5601,9^{*}$ & 0,059 \\
\hline Nasdaq & 0,002 & $-4783,5^{*}$ & $0,117^{* *}$ & 0,003 & $-8264,5$ & 0,131 \\
\hline
\end{tabular}

* Parameters statistically significant at a 5\% confidence level.

** Heteroskedasticity found and corrected using the White method.

*** Autocorrelation and Heteroskedasticity were found and corrected by using the Newey-West method.

Table 9 - Announcements and Business Cycle (Michigan University Confidence Index) 


\begin{tabular}{|c|c|c|c|c|c|c|c|c|}
\hline & \multicolumn{8}{|c|}{ (Equation $\left.10 \Delta P_{t}=\beta_{1}+\beta_{2} D_{E X P}\left(\pi_{t}-\pi_{t}^{e}\right)+\beta_{3} D_{A B R}\left(\pi_{t}-\pi_{t}^{e}\right)+\varepsilon_{t}\right)$} \\
\hline & \multicolumn{4}{|c|}{ CPI } & \multicolumn{4}{|c|}{ CPI Core } \\
\hline & $B_{1}$ & $B_{2}$ & $B_{3}$ & $R^{2}$ & $B_{1}$ & $B_{2}$ & $B_{3}$ & $R^{2}$ \\
\hline S\&P500 & $-0,001$ & $-2,82$ & $-5,84^{*}$ & 0,138 & $-0,001$ & $-4,25$ & $-8,55$ & 0,145 \\
\hline S\&Paero & $-0,001$ & $-1,46$ & $-3,85$ & 0,055 & $-0,001$ & $-1,32$ & $-4,32$ & 0,031 \\
\hline S\&Pauto & $-0,001$ & $-4,46$ & $-9,05^{*}$ & 0,168 & $-0,001$ & $-2,28$ & $-10,77^{*}$ & 0,097 \\
\hline S\&Pbank & $-0,000$ & $-1,88$ & $-8,09^{*}$ & 0,141 & $-0,001$ & $-4,41$ & $-12,82^{*}$ & 0,172 \\
\hline S\&Pcmhw & $-0,003$ & $-9,21^{*}$ & $-7,67^{*}$ & 0,134 & $-0,002$ & $-9,92^{*}$ & $-13,31^{*}$ & 0,154 \\
\hline S\&Poilp & $-0,000$ & 3,94 & $-4,46$ & 0,053 & $-0,002$ & 3,29 & $-1,92$ & 0,012 \\
\hline S\&Pphar & $-0,003$ & $-2,17$ & $-7,83^{*}$ & 0,105 & $-0,003$ & $-3,34$ & $-7,93$ & 0,054 \\
\hline Nasdaq & $-0,001$ & $-4,07$ & $-6,83^{*}$ & 0,093 & $-0,001$ & $-6,26$ & $-12,6$ & 0,146 \\
\hline
\end{tabular}

* Parameters statistically significant at a $5 \%$ confidence level.

** Heteroskedasticity found and corrected using the White method.

*** Autocorrelation and Heteroskedasticity were found and corrected by using the Newey-West method.

Table 10 - Hypothesis Test: Announcements and Business Cycle (Michigan University Confidence Index) derived from Equation 10

\begin{tabular}{lcccc}
\hline & \multicolumn{2}{c}{ CPI } & \multicolumn{2}{c}{ CPI Core } \\
\hline S\&P500 & $\beta_{2}=B_{3}=0$ & $\beta_{2}=0$ & $\beta_{2}=B_{3}=0$ & $\beta_{2}=0$ \\
S\&Paero & 0,006 & 0,269 & 0,025 & 0,054 \\
S\&Pauto & 0,138 & 0,590 & 0,334 & 0,664 \\
S\&Pbank & 0,002 & 0,208 & 0,029 & 0,574 \\
S\&Pcmhw & 0,005 & 0,570 & 0,001 & 0,222 \\
S\&Poilp & 0,007 & 0,031 & 0,003 & 0,037 \\
S\&Pphar & 0,153 & 0,282 & 0,652 & 0,425 \\
Nasdaq & 0,021 & 0,572 & 0,147 & 0,443 \\
\hline
\end{tabular}

* Parameters statistically significant at a 5\% confidence level.

** Heteroskedasticity found and corrected using the White method.

*** Autocorrelation and Heteroskedasticity were found and corrected by using the Newey-West method.

Table 11 - Announcements and Business Cycle (Conference Board Confidence Index)

\begin{tabular}{|c|c|c|c|c|c|c|c|c|}
\hline & \multicolumn{8}{|c|}{ (Equation $\left.10 \Delta P_{t}=\beta_{1}+\beta_{2} D_{E X P}\left(\pi_{t}-\pi_{t}^{e}\right)+\beta_{3} D_{A B R}\left(\pi_{t}-\pi_{t}^{e}\right)+\varepsilon_{t}\right)$} \\
\hline & \multicolumn{4}{|c|}{ CPI } & \multicolumn{4}{|c|}{ CPI Core } \\
\hline & $B_{1}$ & $B_{2}$ & $B_{3}$ & $R^{2}$ & $B_{1}$ & $B_{2}$ & $B_{3}$ & $R^{2}$ \\
\hline S\&P500 & $-0,002$ & $-3,86$ & $-5,57^{*}$ & 0,131 & $-0,001$ & $-7,01^{*}$ & $-5,84$ & 0,130 \\
\hline S\&Paero & $-0,001$ & $-2,38$ & $-3,55$ & 0,050 & -0001 & $-4,26$ & $-1,50$ & 0,029 \\
\hline S\&Pauto & $-0,002$ & $-7,19^{*}$ & $-7,62^{*}$ & 0,155 & $-0,001$ & $-9,76^{*}$ & $-3,59$ & 0,082 \\
\hline S\&Pbank & $-0,001$ & $-4,04$ & $-7,52$ & 0,123 & $-0,001$ & $-8,43^{*}$ & $-8,78^{*}$ & 0,138 \\
\hline S\&Pcmhw & $-0,004$ & $-10,36^{*}$ & $-6,32^{*}$ & 0,141 & $-0,003$ & $-14,21^{*}$ & $-9,27$ & 0,157 \\
\hline S\&Poilp & $-0,001$ & 2,33 & $-4,84$ & 0,043 & $-0,002$ & $-2,07$ & 3,19 & 0,011 \\
\hline S\&Pphar & $-0,003$ & $-3,08$ & $-8,25^{*}$ & 0,103 & $-0,003$ & $-5,61$ & $-5,66$ & 0,046 \\
\hline Nasdaq & $-0,002$ & $-5,83$ & $-5,85$ & 0,088 & $-0,001$ & $-10,18^{*}$ & $-8,74$ & 0,132 \\
\hline
\end{tabular}

* Parameters statistically significant at a 5\% confidence level.

** Heteroskedasticity found and corrected using the White method.

*** Autocorrelation and Heteroskedasticity were found and corrected by using the Newey-West method.

Table 12 - Hypothesis Test: Announcements and Business Cycle (Conference Board Confidence Index) derived from (Equation 10 
INFLATION ANNOUNCEMENTS, FEDERAL RESERVE BIAS AND STOCK RETURNS

\begin{tabular}{lcccc}
\hline & \multicolumn{2}{c}{ CPI } & \multicolumn{2}{c}{ CPI Core } \\
\hline & $\beta_{2}=B_{3}=0$ & $\beta_{2}=0$ & $\beta_{2}=B_{3}=0$ & $\beta_{2}=0$ \\
\hline S\&P500 & 0,007 & 0,084 & 0,005 & 0,002 \\
S\&Paero & 0,166 & 0,314 & 0,133 & 0,053 \\
S\&Pauto & 0,003 & 0,022 & 0,052 & 0,025 \\
S\&Pbank & 0,010 & 0,168 & 0,005 & 0,031 \\
S\&Pcmhw & 0,005 & 0,006 & 0,003 & 0,005 \\
S\&Poilp & 0,217 & 0,465 & 0,670 & 0,632 \\
S\&Pphar & 0,023 & 0,356 & 0,195 & 0,221 \\
Nasdaq & 0,040 & 0,083 & 0,003 & 0,001 \\
\hline
\end{tabular}

* Parameters statistically significant at a 5\% confidence level.

** Heteroskedasticity found and corrected using the White method.

*** Autocorrelation and Heteroskedasticity were found and corrected by using the Newey-West method.

Table 13 - Stock Prices and Federal Reserve Bias

\begin{tabular}{lcccccccccc}
\hline \multicolumn{10}{c}{ CPI } \\
\hline \multicolumn{10}{c}{$\left.\boldsymbol{B}_{t}=\beta_{1}+\beta_{2} D_{1}\left(\pi_{t}-\pi_{t}^{e}\right)+\beta_{3} D_{2}\left(\pi_{t}-\pi_{t}^{e}\right)+\beta_{4} D_{3}\left(\pi_{t}-\pi_{t}^{e}\right)+\varepsilon_{t}\right)$} \\
\hline S\&P500 & $B_{1}$ & $B_{2}$ & $B_{3}$ & $B_{4}$ & $R^{2}$ & $B_{1}$ & $B_{2}$ & $B_{3}$ & $B_{4}$ & $R^{2}$ \\
S\&Paero & $-0,002$ & $-2,74$ & $-6,58^{*}$ & $-5,00$ & $0,140^{* *}$ & $-0,002$ & $-3,82$ & $-2,36$ & $-14,35^{*}$ & 0,216 \\
S\&Pauto & $-0,002$ & $-6,44$ & $-3,34$ & $-4,75$ & 0,066 & $-0,002$ & 1,14 & 1,11 & $-12,10^{*}$ & 0,135 \\
S\&Pbank & $-0,002$ & $-4,22$ & $-8,06^{*}$ & $-5,56$ & $0,121^{* *}$ & $-0,002$ & $-4,35$ & $-5,18$ & $-17,64^{*}$ & 0,202 \\
S\&Pcmhw & $-0,003$ & $-7,30$ & $-6,58^{*}$ & $-10,18$ & $0,139^{* *}$ & $-0,003$ & $-11,67$ & $-0,12$ & $-26,20^{*}$ & 0,279 \\
S\&Poilp & $-0,002$ & $-0,82$ & 0,26 & $-3,29$ & 0,014 & $-0,003$ & 6,92 & 3,51 & $-9,68$ & 0,079 \\
S\&Pphar & $-0,004$ & $-2,57$ & $-5,75$ & $-8,42^{*}$ & 0,102 & $-0,004$ & $-1,44$ & $-1,08$ & $-16,00^{*}$ & 0,111 \\
Nasdaq & $-0,002$ & $-2,97$ & $-5,87^{*}$ & $-8,07$ & $0,100^{* * *}$ & $-0,001$ & $-6,85$ & $-1,67$ & $-22,12^{*}$ & $0,24^{* *}$ \\
\hline
\end{tabular}

* Parameters statistically significant at a $5 \%$ confidence level.

** Heteroskedasticity found and corrected using the White method.

*** Autocorrelation and Heteroskedasticity were found and corrected by using the Newey-West method. 